\title{
The Role of IQ, Expertise, and Motivation in the Recall of Familiar Information
}

\author{
DaVid F. BJoRKLUND \\ Florida Atlantic University \\ Wolffgang Schneider \\ Universität Würzburg \\ KATHERINE KiPP HARNISHFEger \\ University of Georgia \\ William S. Cassel and Barbara R. BJorklund \\ Florida Atlantic University \\ AND \\ JEAN E. BERNHOLTZ
University of Miami
}

High- and low-IQ children in the first, third, and fifth grades performed two free-recall tasks: a sort-recall task with sets of categorically related pictures, and a class-recall task, with children recalling the current members of their school class. All children were deemed to be experts concerning the composition of their school class, but, unlike experts in other domains, had no special motivation associated with their expertise. Recall and clustering on both tasks were high. The high-IQ children performed better than low-IQ children only on the sort-recall task. IQ was significantly correlated with measures of performance on the sort-recall task but not on the class-recall task. The results reflect the fact that the memory benefits associated with being an expert (here, elimination of IQ effects) are related to the greater knowledge the expert possesses and not to factors of motivation. 1992 Academic Press, Inc.

Recent research has emphasized the importance of knowledge base as a causal factor in developmental changes in memory performance (see Bjorklund, 1987; Bjorklund, Muir-Broaddus, \& Schneider, 1990; Chi, 1985; Ornstein, Baker-Ward, \& Naus, 1988; Schneider \& Pressley, 1989).

This research was supported by a grant from the Spencer Foundation. We thank the staff and students of S. D. Spady, Whispering Pines, and Henderson University Elementary Schools for their cooperation in conducting this study. We also thank Patricia Page, Thomas Coyle, and Cherie Everett for assistance in collecting and analyzing data. Portions of this study were reported at the meeting of the Society for Research in Child Development, Seattle, WA. Requests for reprints should be sent either to David F. Bjorklund, Department of Psychology, Florida Atlantic University, Boca Raton, FL 33431 (E-mail address: BJORKLDF@FAUVAX.BITNET), or to Wolfyang Schneider, Department of Psychology, Universität Würzburg, Wittelsbachplatz 1, D-8700, Würzburg, Germany (E-mail address: WSchneider@VAX.rz.Uni-Wuerzburg.dbp.de). 
Older children, having greater content knowledge for the to-beremembered information, expend less mental effort in retrieving individual items from long-term memory and more easily implement memory strategies, relative to younger children. Differences in knowledge base have also been hypothesized to be a major source of individual differences in memory (see Muir-Broaddus \& Bjorklund, 1990; Schneider, Körkel \& Weinert, 1989, 1990). One very fruitful area of research concerning individual differences in memory performance as a function of differences in knowledge base has concentrated on differences between experts and novices in particular domains (e.g., Chi, 1978; Voss, Vesonder, \& Spilich, 1980). Experts in an area display greater retention of relevant information than nonexperts, although they do not differ from novices in areas unrelated to their expertise. In fact, in one much cited study (Chi, 1978), chess-expert children displayed greater memory span for chess positions than a group of adults, although the pattern of results was reversed when digits were used as stimuli (see also Opwis, Gold, Gruber, \& Schneider, 1990).

This expert/novice paradigm has been expanded upon by assessing the memory of children with different levels of expertise orthogonal to indices of their intelligence. For example, Schneider et al. $(1989,1990)$ classified third, fifth, and seventh grade children as soccer experts or novices. Assessments were also made of children's academic performance (IQ scores and school grades), permitting them to classify subjects as successful or unsuccessful learners. This yielded four distinct groups: soccer experts/successful learners; soccer experts/unsuccessful learners; soccer novices/successful learners; and soccer novices/unsuccessful learners. Children from each group were read a story about soccer and later asked a series of memory and comprehension questions about the passage. The most striking aspect of their results was that, at each grade level, soccer experts remembered more about the story and showed greater comprehension than soccer novices, independent of learning ability. That is, individual differences in intelligence did not contribute at all to differences in performance for this material. Similar findings of the moderating effect of knowledge on low levels of intelligence (or aptitude) in the retention of domain-specific information have been reported in two other studies assessing junior high school children's (Recht \& Leslie, 1988 ) and adults' (Walker, 1987) knowledge of baseball. In a similar vein, Swanson (1990) has recently reported that high metacognitive knowledge can compensate for low general aptitude in children's cognitive task performance. Similar to the interpretation of knowledge base theorists, Swanson argues that metacognitive skill substitutes for general ability "by providing children with domain-specific problem-solving aptitude" (1990, p. 313). 
In investigating the relationship between expertise and intelligence on memory performance, we do not mean to imply that psychometric intelligence is independent of content knowledge. Consistent with contemporary theories of intelligence (e.g., Ceci, 1990; Sternberg, 1985), we believe that what children know is an important component of intelligence, influencing how efficiently information is processed and the likelihood of acquiring new information. Yet recent research has clearly shown that low IQ children can develop pockets of expertise, and when they do, they perform in a highly competent manner on cognitive tasks dealing with their area of expertise. Thus, we see domain-specific knowledge as compensating for generally low psychometrically measured intelligence when the tasks permit children to use their detailed knowledge for problem solution. In such situations, children's expertise "makes" them smart, reflecting, we believe, the important role that knowledge plays in "intelligent" behavior. This also suggests that the academic performance of low-IQ children can be enhanced when instruction is conducted (1) in a domain for which they have substantial knowledge or (2) in a manner whereby the child's knowledge is built step by step so that he or she develops a substantial knowledge base with which to compensate for the lower IQ.

As important as the expert/novice studies are in clarifying the relation between content knowledge and intelligence for retention of domainspecific information, there are some problems inherent with the expert/ novice paradigm. One usual problem, that of potential differences in intelligence of experts and novices, is solved by studies such as those of Schneider et al. $(1989,1990)$ by contrasting expert groups orthogonal to intelligence level groups. However, the role of motivation remains an issue. Children (and adults) who choose to become expert at a subject likely are especially motivated to perform well on tasks assessing knowledge pertinent to their domain of expertise. Based on previous studies by Schneider and his collcagues on soccer expertisc (Schncider \& Bjorklund, 1992; Schneider et al., 1989), there is clear evidence that child experts are more interested in and motivated to engage in tasks related to their field of expertise than are novices. Furthermore, there is no evidence the highand low-aptitude experts differ in regard to either interest (Schneider \& Bjorklund, 1992) or motivation (Schneider et al., 1989). In other words, expert children are different from nonexpert children in important ways other than just their knowledge base. Although there is little research specifically investigating this question, motivation has been theorized to be an important component in children's memory performance (see Schneider \& Pressley, 1989), with some research indicating higher levels of memory performance for children who are given incentives to perform well (e.g., Kunzinger \& Witryol, 1984). 
Research by Bjorklund and Zeman has sought to avoid this problem by assessing children's memory for a domain in which all children can be considered as experts, namely for recall of the members of their current school class (Bjorklund \& Bjorklund, 1985; Bjorklund \& Zeman, 1982, 1983). When tested at the end of the school year, children from the first grade on are highly familiar with the composition of their school class. Research has shown that levels of recall and clustering (based on structures in the classroom such as seating arrangement or reading groups, or in terms of characteristics of the children themselves, such as sex or race) are high, with developmental differences being greatly reduced or eliminated. Furthermore, although most children appear to follow some clustering strategy in their recall, a majority of children of all ages tested ( 6 to 11 years) are unaware of using a particular organizational scheme.

Bjorklund and Zeman have argued that the organization observed in class recall reflects, for the most part, the relatively automatic activation of well-established relations in long-term memory and not deliberately implemented strategies, per se. Following the theorizing of Hasher and Zacks (1979), because of the automatic nature of such organization, performance should not vary with individual differences in motivation or intelligence.

Children, because of their daily exposure to and involvement with classmates and their names, can be considered experts in the knowledge of the names to be recalled. Although one's classmates are surely important to a child, the frequent practice, studying, and general investment of time associated with expertise in areas such as chess or baseball should not characterize children's expertise in knowing their classmates' names. Thus, there should be no special motivation to perform well in the classrecall task. In comparison, one hypothesis for the generally superior performance of experts relative to novices independent of aptitude, is that children who choose to become especially proficient in domains such as soccer, chess, or baseball are particularly motivated to do well on tasks within their area of expertise. Performance between high- and low-IQ children on the class-recall task can be compared with the results of other studies using the expert/novice paradigm, with the knowledge that patterns of performance between the high- and low-IQ children are not attributed to a special motivation typically associated with being an expert. If the performance differences between low- and high-IQ experts and nonexperts (which were found in previous expert/novice studies) were not due to differences in motivation, then we should find no significant relationships between class-recall performance and measures of IQ in the present study.

Children from grades 1, 3, and 5 were administered the class-recall task and a sort-recall task, in which they were given a set of categorizable 
pictures to sort into meaning-based groups and then to recall. The classrecall task is hypothesized to be mediated by the relatively automatic activation of well-established semantic memory relationships. In contrast, the sort-recall task is hypothesized to involve a significant strategic component, with subjects actively deciding how to group items into coherent categories to facilitate retrieval (see Schneider \& Pressley, 1989). Children's recall and clustering on sort-recall tasks when they are directed to group items according to categories is often high (see Bjorklund et al., 1990) and should approximate that of class recall, making comparisons between the two tasks appropriate. Children were further classified into high-IQ or low-IQ groups. Thus, in this study, the effects of individual differences in intelligence on memory tasks were assessed in children on two tasks, the class-recall task for which they could be considered experts, and one "standard" (sort-recall) task for which they were not experts. We predicted that individual differences in IQ would influence performance on the sort-recall task but would not significantly influence performance on the class-recall task.

\section{METHOD}

Subjects. Subjects in this experiment were 47 first graders $(21$ boys and 26 girls, mean age $=7.3$ years, $S D=.42$ years) from five different classrooms; 54 third graders ( 24 boys and 30 girls, mean age $=9.5$ years, $S D=.47$ years) from four different classrooms; and 52 fifth graders ( 24 boys and 28 girls, mean age $=11.26$ years, $S D=.44$ years) from four different classrooms. Children were selected from two public schools in south Florida. The families of the children represented a broad socioeconomic range, but most were from lower-middle to upper-middle income brackets. Children had been assigned to their classrooms at the beginning of the school year, approximately 8 months prior to testing. Although seating arrangements in each of the 13 classrooms involved in this study were not uniform, structurcd arrangements were used in each classroom.

Children were classified into high- or low-IQ groups based on a median split of IQ scores computed separately at each grade. For the third (low $M=104.03, S D=9.67$; high $M=$ $126.38, S D=8.74$ ) and fifth grade children (low $M=96.61, S D=8.77$; high $M=120.17$, $S D=10.36$ ), classifications were based on scores from the Otis-Lennon test, administered by the school at the end of the previous academic year. Such tests were not available for the first grade students. These children were classified into IQ groups based on scores on the vocabulary subtest of the WISC-R, which was administered to all children during the experimental session (low $M=74.73, S D=12.17$; high $M=103.62, S D=12.46$ ).

Tasks, materials, and procedure. All children were seen individually and administered two free-recall tasks in counterbalanced order, separated by a brief interpolated activity (digit span). For the sort-recall task, children received two trials on one of two sets of black-and-white line drawings from familiar natural language categories (see Table 1). Highly familiar and category typical items were selected for this task, so that the children might spontaneously use an organizational strategy. Third and fifth grade children were presented with 20 items, whereas 16-item lists were used for the first grade children.

For the sort-recall task, the items from one of the lists were placed on a table in front of children in one of two predetermined random orders, with children naming each card as it was placed on the table. Children were told that the purpose of the task was to remember 
TABLE 1

Stimulus Lists UsEd for Sort-Recall Task

\section{List 1}

Fruit: banana, ${ }^{a}$ apple, pear, grapes, cherries

Furniture: couch, ${ }^{a}$ table, desk, chair, lamp

Clothing: pants, ${ }^{a}$ coat, socks, dress, gloves

Tools: wrench, ${ }^{a}$ hammer, drill, axe, pliers

List 2

Vehicles: car, ${ }^{a}$ bus, train, airplane, bicycle

Body parts: leg, ${ }^{a}$ finger, ear, elbow, foot

Weapons: cannon, ${ }^{a}$ knife, gun, sword, spear

Vegetables: carrot, ${ }^{a}$ lettuce, cucumber, corn, celery

${ }^{a}$ Items not included in the lists for the first grade children.

as many of the pictures as they could, and that they would have 2 min to study the cards. They were told to sort the pictures into groups of things that go together or are alike in some way in preparation of a memory test. Following the 2 -min sorting period, the cards were covered by a black cloth and children were given a visual match-to-sample task (the Matching Familiar Figures Test) for $30 \mathrm{~s}$ as a buffer-clearing task. Children were then asked to recall as many items from the list as they could in any order that they liked. If a child remained silent for $10 \mathrm{~s}$, the experimenter asked if he or she could remember any more items. After another 10-s interval or when the child announced that he or she could remember no more, the trial was ended. The second sort-recall trial, using the same items presented in a different random order, was then begun, following the same procedure as trial 1 .

Children's sorting was videotaped, and the tapes were later used to determine children's sorting patterns. Before the experimental lists were given to the children, they received a six-item practice trial to familiarize them with the sort-recall task. Typically, children's categorization was obvious in that it followed natural language categories as depicted in Table 1. Fruits were categorized with fruits, furniture with furniture, and so on. Observation and evaluation of the physical sorting was, for the most part, also obvious, with children grouping their sorted cards in relatively tight groups with sufficient spaces between the sorted groups to indicate group separation. On those few occasions that included some ambiguity, the tapes were viewed by no fewer than three evaluators and consensus was obtained.

The class-recall task was administered following the procedures developed by Bjorklund and Zeman (1982). Children were first asked the number of children in their current class and then asked to remember as many of those children as they could, in any order they wished. When $10 \mathrm{~s}$ passed without a response, the children were asked if they could remember any more names and to think for a few more seconds about the class. After a second 10-s period in which no new name was recalled or after children said that they could recall no more names, the trial was ended.

Immediately following class recall, children were asked questions designed to determine if they were aware of using any specific strategies in the task. They were first asked how they were able to remember so many of their classmates. If they gave no specitic answer (e.g., "I don't know" or "I used my brain"), they were asked if there was any special way in which they recalled the names. If again the answer was negative, they were asked, "Did you name the children in any special order?" If the child described an organizational strategy in reply to any of the three questions, it was compared to the organizational scheme 
actually shown in the child's recall (as reflected by the clustering scores). The entire classrecall procedure was audiotaped.

\section{RESULTS}

\section{Preliminary Analyses}

Preliminary analyses of percentage recall, clustering, and sorting scores revealed no significant main or interactive effects attributed to sex. Therefore, all subsequent analyses will be reported collapsed across sex. Also, in most contrasts with class recall, mean performance on the two sort-recall trials is used. Recall and clustering were generally higher on the second sort-recall trial than the first, but the pattern with respect to class recall was statistically identical for each trial. For all analyses, results are reported at $p<.05$ and significant effects were assessed via Neumann-Keuls tests unless otherwise specified.

\section{Recall}

Percentage recall was analyzed in a 3 (grade: first, third, fifth) $\times 2$ (IQ group: high, low) $\times 2$ (task: class recall, mean sort recall) analysis of variance, with repeated measures on the task factor. These data are shown in Table 2 . As can be seen, level of performance was relatively high for children at each grade level for both the class-recall and sortrecall tasks. The analysis produced significant main effects of grade, $F(2,147)=33.66, M S_{\mathrm{e}}=213.91$ [fifth $(83.86 \%)=$ third $(80.04 \%)>$ first $(67.6 \%)$ ]; IQ group, $F(1,147)=9.3$ [high $(80.03 \%)>$ low $(75.34 \%)$ ]; and task, $F(1,147)=22.63, M S_{\mathrm{e}}=127.69$ [sort recall $(80.58 \%)>$ class recall $(74.45 \%)]$. Also significant were the grade $\times$ task, $F(2,147)=3.30$, and IQ group $\times$ task, $F(1,147)=9.16$, interactions.

Inspection of the significant grade $\times$ task interaction revealed that recall on sort recall was significantly greater than on class recall for both the third and fifth graders, $t \mathrm{~s}(147) \geqslant 3.76,(84.17 \%$ vs $75.91 \%$ for the third graders and $88.03 \%$ vs $79.69 \%$ for the fifth graders). This difference was not significant for the first grade children $(68.22 \%$ vs $66.98 \%, t(147)<1)$. The IQ group $\times$ task was the critical interaction for the purposes of this study. As predicted, there was no difference in percentage recall between the high-IQ $(74.96 \%)$ and low-IQ $(74.01 \%)$ groups for the class-recall task, $t(294)<1$. In contrast, the high-IQ children recalled significantly more items than the low-IQ children on the sort-recall task $(85.1 \%$ vs $76.67 \%$, $t(294)=3.99)$.

\section{Clustering}

The Adjusted Ratio of Clustering (ARC) score (Roenker, Thompson, \& Brown, 1971) was used as a measure of clustering in recall for the classrecall task. Perfect clustering is set at an ARC score of 1.0, chance clus- 
TABLE 2

Mean Percentage Recall and Clustering by Grade, IQ Level, and Task

\begin{tabular}{ccc}
\hline & High IQ & Low IQ \\
\hline First grade & $74.3(.71)$ & $62.4(.56)$ \\
Sort Recall & {$[18.9]$} & {$[15.1]$} \\
Class Recall & $66.4(.39)$ & $67.5(.51)$ \\
& {$[18.5]$} & {$[15.6]$} \\
Third grade & & \\
Sort Recall & $88.6(.90)$ & $80.6(.85)$ \\
& {$[8.9]$} & {$[11.8]$} \\
Class Recall & $75.5(.43)$ & $76.3(.52)$ \\
& {$[11.1]$} & {$[15.0]$} \\
Fifth grade & & $84.7(.90)$ \\
Sort Recall & $91.9(.91)$ & {$[9.9]$} \\
& {$[7.5]$} & $77.2(.56)$ \\
Class Recall & $82.6(.61)$ & {$[9.8]$} \\
\hline
\end{tabular}

Note. ARC scores are in parentheses. Standard deviations are in brackets.

tering is set at 0 , and negative values represent clustering less than expected by chance. ${ }^{1}$ As in previous work (e.g., Bjorklund \& Zeman, 1982, 1983 ), clustering for class recall was computed based on several possible organizations (i.e., reading groups, seating groups, sex, race, etc.) with a child's highest ARC score being used in all subsequent analyses. The categories used to determine the ARC scores in class recall were predetermined, based on structures present in the classrooms (e.g., seating arrangements, reading groups), characteristics of the children (e.g., sex,

' The ARC score was chosen as a measure of clustering because it possesses certain features desirable when comparisons of organization are to be made among lists of varying lengths and over conditions where recall is expected to differ (e.g., item recall vs, class recall). First of all, the ARC score has been found to vary independently of level of recall (Murphy, 1979). That is, unlike some other indices, high levels of recall do not in and of themselves produce high levels of organization. Furthermore, ARC scores do not systematically vary with the number of categories presented in a list. That is, the ARC scores will not necessarily be higher when a "list" consists of only two or three categories than when the same list is divided into five or more categories. Thus, we can make comparisons of organization between children who organize their class recall by sex (two categories) with those who organize on the basis of reading groups (five or six categories), knowing that levels of organization will be independent of the number of possible categories in the lists. 
race), and other information provided to us by each teacher (e.g., groups of friends, transportation groups).

Mean clustering (ARC) scores are presented by grade, IQ group, and task in Table 2. Clustering in sort recall was based on the groups each child had made during the sorting phase of the experiment. A child's mean clustering on the two sort-recall trials was used in the following analyses for the sort-recall data.

The analysis of the clustering data produced significant main effects of grade, $F(2,147)=20.05, M S_{\mathrm{e}}=.052$ [fifth $(.74)=$ third $(.67)>$ first (.54)], and task, $F(1,147)=191.92, M S_{e}=.037$ [sort recall $(.81)>$ class recall (.50)]. Also significant were all interactions involving task: grade $\times$ task, $F(2,147)=8.47$; IQ group $\times$ task, $F(1,147)=7.6$; and grade $\times$ IQ group $\times$ task, $F(2,147)=3.81$. An inspection of the significant three-way interaction revealed no differences in clustering between the high- and low-IQ groups at any grade for class recall. For the sort-recall task, clustering was significantly greater for the high-IQ group than the low-IQ group only for the first graders, $t(294)=2.45$. The lack of difference between the two IQ groups for the sort-recall task for the third and fifth grade children can be attributed to ceiling levels of clustering performance. As can be seen from Table 2, clustering on sort recall was uniformly high for the third and fifth graders, reflecting these subjects' effective use of a categorical strategy to mediate their recall performance. Although clustering in class recall was also high relative to that typically found in free-recall tasks, it did not approach ceiling levels.

\section{Organization at Sorting}

The extent to which subjects organized their groups according to adultdefined categories ${ }^{2}$ was evaluated for the two sort-recall trials by computing ARC scores that assessed the composition of children's sorts as a function of adult categories (hereafter referred to as sorting). Children of all grades easily sorted items according to the adult criteria (mean sorting per grade: first $=.76$; third $=.98 ;$ fifth $=.95$ ). A grade $\times$ IQ group $\times$ trial analysis of variance, performed on the sort-recall data, produced significant effects of grade, $F(2,147)=15.39, M S_{\mathrm{e}}=.08$ (fifth $=$ third $>$ first), and IQ group, $F(1,147)=4.80$ [high IQ $(M=.94)>$ low IQ $(M=.86)$ ]. There were no other significant effects in the analysis of the sorting data.

\footnotetext{
${ }^{2}$ Adult-defined categories are those natural language categories that define, in a single word or phrase, various typical or common items. Table 1 contains the sort-recall task categories and their contents.
} 
TABLE 3

Correlations of Recall, Clustering, and Sorting with IQ for Class Recall and Trials 1 and 2 of Sort Recall

\begin{tabular}{lccc}
\hline & Recall & Clustering & Sorting \\
\hline First grade $(n=46)$ & & & \\
Class recall & .04 & -.13 & $.32^{*}$ \\
Sort recall 1 & $.39^{*}$ & .18 & .11 \\
Sort recall 2 & $.42^{*}$ & $.26^{*}$ & \\
Third grade $(n=54)$ & & & \\
Class recall & .12 & $-.24^{*}$ & .20 \\
Sort recall 1 & $.27^{*}$ & .17 & .19 \\
Sort recall 2 & $.53^{*}$ & .06 & \\
Fifth grade $(n=52)$ & & & .08 \\
Class recall & .18 & .09 & -.05 \\
Sort recall 1 & $.27^{*}$ & .07 & .18 \\
Sort recall 2 & .20 & & \\
\hline
\end{tabular}

$* p<.05$.

\section{Correlations of Recall, Clustering, and Sorting with $I Q^{3}$}

Table 3 presents correlations of recall, clustering, and sorting with IQ, separately for the class-recall and sort-recall tasks (note that correlations with sorting scores were available only on the sort-recall task). As can be seen, there were no significant positive correlations between IQ and recall or clustering at any grade level for the class-recall task. The only significant correlation between class-recall performance and IQ was a negative one for clustering of the third graders. In contrast, significant correlations with recall on the sort-recall task were found in five of six possible instances. There was only one significant correlation between clustering and IQ for the sort-recall task, and that was for the first graders on trial 2. As we mentioned before, clustering in recall was at ceiling levels for the two groups of older children, attenuating any correlational effect. A similar pattern was observed between IQ and sorting on the sort-recall task, with a significant correlation being found only for the first graders (trial 1).

Correlations were also computed between the recall and clustering scores. It was assumed that if levels of recall are mediated by strategic organization, then the correlation between recall and clustering measures

${ }^{3}$ Because near-ceiling level performance by the older children on some of the measures could attenuate correlations calculated from raw scores, both Spearman rank-order correlations and Pearson correlations were computed for each comparison. Patterns of correlations were nearly identical for every comparison; therefore, only Pearson correlation values are reported. 
would be significant and high (cf. Bjorklund \& Jacobs, 1985; Frankel \& Rollins, 1982; Jablonski, 1974). The correlations between recall and clustering in class recall were negative and nonsignificant at each grade level $(r \mathrm{~s}=-.17,-.08$, and -.21 for the first, third, and fifth graders, respectively). In contrast, the correlations between recall and clustering were significant $(p<.05)$ in three out of six comparisons for the sort-recall task [first grade: trial $1=.30$, trial $2=.39$; fifth grade, trial $1=.29$; the correlations were not significant for the third graders on trials $1(r=.17)$ and $2(r=.07)$, or for the fifth graders on trial $2(r=.05)]$. Again, the ceiling level clustering scores for the third and fifth graders attenuated correlations with recall.

\section{Children's Awareness of Strategies in Class Recall}

Following the completion of class recall, children were asked if they had remembered their classmates' names in any special order or way. Children who professed a strategy consistent with that observed (i.e., one that corresponded to their highest ARC score) were classified as Consistent. Representative examples of strategies that children professed included seating arrangement ("Looking at tables in my head," "I pictured the room and where everybody sits"), alphabetical ("I thought of the roll call and the names on it"), or activity groups ("I thought of the kids in my math/reading/spelling group"). Other explanations children gave about how they remembered their classmates' names could not be evaluated. These included statements such as "Thinking," "I talk to them everyday," or "I just know them."

Those who professed either no strategy or one inconsistent with that observed in their recall were classified as Not Consistent. A typical example of an inconsistent strategy response would be a child who professed to using the teacher's roll call to remember his or her classmates, but actually recalled them (as reflected by ARC scores) according to reading groups (and the roll call was not in reading group order). As in previous work (Bjorklund \& Zeman, 1982), the majority of children at each grade level were classified as Not Consistent, although the first graders were slightly more likely to be so classified than the older children (percent classified as Not Consistent $=77,56$, and $62 \%$ for the first, third, and fifth graders, respectively, $\chi^{2}(2)=5.05, p=.08$ ). Low-IQ subjects were equally likely to be classified as Consistent $(36 \%)$ as were high-IQ subjects $(42 \%), x^{2}(1)<1 .^{4}$

\footnotetext{
${ }^{4}$ As in earlier class-recall studies, children who were classified as Consistent had higher recall and clustering scores than those of children who were classified as Not Consistent, although the absolute levels of performance for the Not Consistent subjects were high in an absolute sense (mean recall, Not Consistent subjects: 71\%; mean clustering: .47).
} 


\section{DISCUSSION}

In this study, high- and low-IQ children's free recall of familiar information was tested in a class-recall task and a sort-recall task. The sortrecall task was chosen because of its significant strategic (i.e., effortful) component and because it was predicted to produce levels of performance comparable to those of class recall. In fact, both levels of recall and clustering were significantly greater for the sort-recall than those for the class-recall task, with clustering being at ceiling levels of performance for sort recall for the third and fifth grade children. Although such high levels of performance were not predicted, they were not entirely unexpected. Past research has shown that children will use a sophisticated organizational strategy in a sort-recall task when they are familiar with the items and their calegorical relations and are instructed to sort items into meaningful groups prior to recall (e.g., Corsale \& Ornstein, 1980).

Despite the high levels of recall and clustering for children on the sortrecall task, levels of performance differed as a function of intelligence. High-IQ children recalled more words on the sort-recall task than low-IQ children at all grade levels. A similar pattern was observed for clustering for the first graders, the only grade for which clustering in sort recall was not at ceiling levels. Correlational analyses confirmed the experimental results, with no significant positive correlations being found between performance measures and IQ for class recall, with five of six correlations between recall and IQ being significant for the sort-recall task. Ceiling performance on the sort-recall task for the third and fifth graders made the correlational pattern for clustering and sorting for these children uninterpretable. Correlations between IQ and clustering and sorting were significant, however, for the first graders, who did not approach ceiling levels on these measures.

When children are expert in a specific domain, they remember information from that domain well, with levels of performance being independent of individual differences in intelligence (Recht \& Leslie, 1988; Schneider et al., 1989; Walker, 1987). This finding was replicated in the current experiment. The major difference between this study and previous expert/novice experiments examining levels of performance as a function of intelligence is that motivation to become an expert was not an issue here. Unlike children who become experts in chess, baseball, or soccer, all children, by the end of the school year, are experts with respect to the composition of their current school class, with no special motivation required to attain this expertise. Thus, the results of this experiment, and by inference the findings of other expert/novice studies, can be attributed to expert children's greater knowledge of the to-be- 
remembered information and not to differential motivation to perform well in their area of specialization.

In previous research, we have found that soccer experts are not only more knowledgeable about soccer than novices, but also more interested in the topic and more highly motivated to perform tasks involving soccer. Although it seems likely that motivation and interest may be reasons for the superior performance of experts versus novices on tasks involving experts' areas of proficiency, these factors do not seem to be responsible for patterns of performance found for high- and low-aptitude experts. For example, in a study by Schneider and Bjorklund (1992), in which soccerexpert children performed a sort-recall task with soccer-related items, there was no difference in interest in soccer between high- and low-IQ experts. Likewise, in the present study, motivation to become an expert was eliminated, yet patterns of performance between the high- and lowIQ children were comparable to that found in other expert/novice studies. Thus, although motivation may play an important role in overall levels of performance, it is not responsible for the patterns observed when highand low-aptitude children serve as subjects. Rather, the knowledge that these experts have, independent of intelligence, seems to be the critical factor in influencing cognitive task performance.

How does being an expert in a domain facilitate processing of domainrelevant information, to the extent that expertise can compensate for individual differences in intelligence? It has been proposed that having detailed knowledge for a domain results in more efficient (i.e., faster) information processing, which affords the individual more mental resources to allocate to various aspects of the task at hand (e.g., Bjorklund, 1987; Bjorklund et al., 1990). This improved efficiency can result in more resources being used for the execution of strategies or in the increased automatization of processes, without the need of deliberate, effortful strategies. In the present experiment, the benefits of expertise were mainly astrategic. As we discussed in the Introduction, performance in class recall has been hypothesized to be mediated by the relatively automatic activation of relations in long-term memory, with deliberate strategies providing little additional benefit to performance (Bjorklund \& Bjorklund, 1985). A majority of children at each grade level were classified as Not Consistent on the class-recall task (i.e., they did not describe an organizational strategy consistent with one observed in their recall), confirming the nonstrategic way in which children performed the task. Yet, levels of performance were nonetheless high. Children classified as Consistent did show a significant recall advantage in class recall $(10 \%)$ relative to children classified as Not Consistent, but the recall of this latter group was still high in absolute terms (71\%). 
Moreover, the correlations between recall and clustering were nonsignificant for class recall (in fact, these correlations were negative at each grade level). Positive correlations between recall and clustering have been interpreted as reflecting the use of a deliberate organizational strategy (Bjorklund \& Jacobs, 1985; Frankel \& Rollins, 1982; Schneider, 1986), with nonsignificant correlations reflecting the fact that performance is mediated by nonstrategic factors. In contrast to class recall, the correlations between recall and clustering were significant for both sort-recall trials for the first graders. Again, ceiling levels of clustering precluded interpreting correlations between recall and ARC scores for the third and fifth graders, but even so, this correlation was significant for the fifth graders on trial 1.

The class-recall task differs from the sort-recall task in ways other than the expertise of the children for the to-be-remembered information. For example, although both tasks require deliberate retrieval of information, the sort-recall task involves a study period, where sets of familiar items must be learned. There is no comparable study period for class recall, with children merely being asked to recall items from long-term memory. The contrast of importance between the two tasks, then, may be the nature of acquisition, and not expertise, per se. Although we cannot rule out this possibility, we believe that expertise is the more critical factor. For example, patterns of performance for the class-recall task are similar to those found for more conventional areas of expertise (e.g., soccer or baseball), with minimal age differences being observed (e.g., Schneider $e t$ al., 1989), and no significant relationship being found between levels of performance and intelligence (e.g., Recht \& Leslie, 1988; Schneider et al., 1989; Walker, 1987).

A more critical difference between the class-recall and sort-recall tasks, we believe, is the fact that performance on class recall is primarily mediated by nonstrategic factors (cf. Bjorklund \& Zeman, 1982), whereas performance on sort recall is greatly facilitated by deliberate strategies (see Bjorklund \& Muir, 1988; Schneider \& Pressley, 1989). Previous studies finding no relation between task performance and intelligence for experts dealing with information from their area of expertise have also used tasks that, in general, do not involve deliberate strategies (i.e., memory span, text processing). Thus, one reason for the different patterns between experts and novices in other studies (e.g., Schneider et al., 1989) and between class recall and sort recall in this study, may be the degree to which deliberate strategies are necessary for successful task solution. However, the results of the present study are similar to those reported in other studies of expertise, all of which used tasks that rely minimally on deliberate, conscious strategies. In sum, the findings of this study illustrate that the memory advantages of a detailed knowledge base can com- 
pensate for individual differences in intelligence, and that these effects are not a function of the special motivation that is often associated with being an expert.

\section{REFERENCES}

BJorkLUND, D. F. (1987). How age changes in knowledge base contribute to the development of children's memory: An interpretive review. Developmental Review, 7, 93-130.

BJorklund, D. F., \& BJorklund, B. R. (1985). Organization versus item effects of an elaborated knowledge base on children's memory. Developmental Psychology, 21, 1120-1131.

BJoRklund, D. F., \& JACOBS, J. W. (1985). Associative and categorical processes in children's memory: The role of automaticity in the development of organization in free recall. Journal of Experimental Child Psychology, 39, 599-617.

BJoRkLUND, D. F., \& Muir, J. E. (1988). Children's development of free recall memory: Remembering on their own. In R. Vasta (Ed.), Annals of child development (Vol. 5, pp. 79-123). Greenwich, CN: JAI.

Bjorklund, D. F., Muir-Broaddus, J. E., \& Schneider, W. (1990). The role of knowledge in the development of children's strategies. In D. F. Bjorklund (Ed.), Children's strategies: Contemporary views of cognitive development (pp. 93-128). Hillsdale, NJ: Erlbaum.

BjoRkLund, D. F., \& Zeman, B. R. (1982). Children's organization and metamemory awareness in their recall of familiar information. Child Development, 53, 799-810.

BJorklund, D. F., \& ZeMAN, B. R. (1983). The development of organizational strategics in children's recall of familiar information: Using social organization to recall the names of classmates. International Journal of Behavioral Development, 6, 341-353.

CECI, S. J. (1990). On intelligence . . . more or less: A bio-ecological treatise on intellectual development. Englewood Cliffs, NJ: Prentice Hall.

CHI, M. T. H. (1978). Knowledge structure and memory development. In R. Siegler (Ed.), Children's thinking: What develops? (pp. 73-96). Hillsdale, NJ: Erlbaum.

CHI, M. T. H. (1985). Interactive roles of knowledge and strategies in the development of organized sorting and recall. In S. F. Chipman, J. W. Segal, \& R. Glaser (Eds.), Thinking and learning skills: Vol. 2. Research and open questions. (pp. 457-483). Hillsdale, NJ: Erlbaum.

Corsale, K., \& Ornstein, P. A. (1980). Developmental changes in children's use of semantic information in recall. Journal of Experimental Child Psychology, 30, 231-245.

Frankel, M. T., \& Rollins, H. A. (1982). Age-related differences in clustering: A new approach. Journal of Experimental Child Psychology, 34, 113-122.

HASHER, L., \& ZaCKS, R. (1979). Automatic and effortful processes in memory. Journal of Experimental Psychology: General, 108, 356-388.

Jablonski, E. M. (1974). Free recall in children. Psychological Bulletin, 81, 522-539.

Kunzinger, E. L., \& Witryol, S. L. (1984). The effects of differential incentives on second-grade rehearsal and free recall. The Journal of Genetic Psychology, 144, 19-30.

Muir-Broaddus, J. E., \& BJorkLund, D. F. (1990). Developmental and individual differences in children's memory strategies: The role of knowledge. In W. Schneider \& F. E. Weinert (Eds.), Interactions among strategies, knowledge, and aptitudes in cognitive performance (pp. 99-116). New York: Springer-Verlag.

MuRPHy, M. D. (1979). Measurement of category clustering in free recall. In C. R. Puff (Ed.), Memory organization and structure (pp. 99-128). New York: Academic Press.

Opwis, K., Gold, A., Gruber, H., \& Schneider, W. (1990). Zum Einfluss von Expertise auf Gedächtnisleistungen und ihre Selbsteinschatzung bei Kindern und Erwachsenen (The impact of expertise on memory performance and performance prediction in chil- 
dren and adults). Zeitschrift für Entwicklungspsychologie und Pädagogische Psychologie, 21, 207-224.

Ornstein, P. A., Baker-Ward, L., \& Naus, M. J. (1988). The development of mnemonic skill. In F. E. Weinert \& M. Perlmutter (Eds.), Memory development: Universal changes and individual differences (pp. 31-50). Hillsdale, NJ: Erlbaum.

RECHT, D. R., \& LESLIE, L. (1988). Effect of prior knowledge on good and poor reader's memory for text. Journal of Educational Psychology, 80, 16-20.

Roenker, D. L., Thompson, C. P., \& Brown, S. C. (1971). Comparison of measures for the estimation of clustering in free recall. Psychological Bulletin, 76, 45-48.

SCHNEIDER, W. (1986). The role of conceptual knowledge and metamemory in the development of organizational processes in memory. Journal of Experimental Child Psychology, 42, 218-236.

SChNeider, W., \& Bjorklund, D. F. (1992). Expertise, aptitude, and strategic remembering. Child Development, 63, 461-473.

Schneider, W., Körkel, J., \& Weinert, F. E. (1989). Domain-specific knowledge and memory performance: A comparison of high- and low-aptitude children. Journal of Educational Psychology, 81, 306-312.

SCHNEIDER, W., \& KöRKEL, J., \& WeinerT, F. E. (1990). Expert knowledge, general abilities, and text processing. In W. Schneider \& F. E. Weinert (Eds.), Interactions among aptitude, strategies, and knowledge in cognitive performance (pp. 235-251). New York: Springer-Verlag.

Schneider, W., \& Pressley, M. (1989). Memory development between 2 and 20. New York: Springer-Verlag.

STERNBERG, R. J. (1985). Beyond IQ: A triarchic theory of human intelligence. New York: Cambridge University Press.

Swanson, H. L. (1990). Influence of metacognitive knowledge and aptitude on problem solving. Journal of Educational Psychology, 82, 306-314.

Voss, J. F., Vesonder, G. T., \& SPILICH, G. J. (1980). Text generation and recall by high-knowledge and low-knowledge individuals. Journal of Verbal Learning and Verbal Behavior, 19, 651-667.

WALKER, C. H. (1987). Relative importance of domain knowledge and overall aptitude on acquisition of domain-related information. Cognition and Instruction, 4, $25-42$. 